\title{
IMAGEN Y DISCURSO DEL «AÑO INTERNACIONAL DE LA MUJER» EN LA PRENSA REGIONAL MURCIANA
}

\author{
Image and discourse of the «International Women's Year» \\ in the Murcian regional press
}

Esther MORA BLEDA

Universidad de Murcia

esther.mora@um.es

Fecha de recepción: 8-II-2012

Fecha de aceptación: 28-II-2012

\begin{abstract}
RESUMEN: En este artículo analizo la conmemoración del «Año Internacional de la $\mathrm{Mu}-$ jer», en 1975, atendiendo a la imagen y discurso que el diario regional murciano, La Verdad, informa para dicho evento. Estructurado en tres apartados, en el primero presento y justifico el sujeto/objeto, el tema, la fuente y el período cronológico y la importancia historiográfica de los mismos. En el segundo apartado, se ubica la celebración del «Año Internacional de la Mujer» a nivel internacional y nacional, así como los motivos que justifican ésta conmemoración, los órganos seleccionados para la organización del evento y los enfoques desde los cuales fue planteado. Por último, se analiza la representación, imagen y discurso que la prensa recoge para este evento. En este punto se estudia la transcendentalidad y repercusión que tuvo para la sociedad «el año de la mujer» y como ésta percibió tanto desde la masculinidad como feminidad dicha conmemoración.
\end{abstract}

Palabras clave: Año Internacional de la Mujer, prensa, sección femenina, organizaciones católicas, asociaciones feministas, año 1975.

ABSTRACT: In this article it is analysed the commemoration, in 1975, of the «International Women's Year», focusing on the image and discourse that the Murcian regional newspaper La Verdad gathered about the said event. It is structured in three different sections. In the first one the subject of analysis, the source, the chronological period, and their historiographic importance are presented and justified. In the second section the celebration of the «International Women's Year» is placed at international and national levels, as well as the reasons that justify this commemoration, the organs selected for the organization 
of the event, and the approaches from which it was considered. Finally, the representation, image and discourse that the press collects for this event are analysed. At this point we study the repercussions that this «year» had on the Murcian and Spanish society, and how this one perceived the aforementioned commemoration, from both the masculinity and the femininity.

Keywords: International Women's Year, press, The Women's Section, Catholic organizations, feminist associations, year 1975.

Poco a poco nos hemos visto recluidas en un apartheid. En muchos apartheids. Entre todos, el más abrumador: el de callar, que es un silenciamiento, no un silencio. Un silenciamiento porque las palabras no traicionan. No dicen nuestro ser. Por tanto, es indispensable seguir escribiendo con palabras nuevas, aquéllas que nos acomoden, que nos expresen, que nos dibujen de cuerpo entero y nos ayuden a darle voz a los vientos que soplan desde el olvido.

(CLARA SCHENER, Tejedoras de Historias, 2006, p. 11)

\section{INTRODUCCIÓN}

El objetivo de este artículo es el estudio, a través del diario regional murciano La Verdad, del «El Año Internacional de la Mujer», conmemorado en el año 1975. En estas líneas iniciales se justifica la temática y fuente seleccionada, y se indica, que este estudio es planteado desde la perspectiva de «las mujeres» como sujeto/objeto, lo que no obvia la influencia del género ${ }^{1}$ como categoría analítica, ni la visión androcéntrica ${ }^{2}$ con la que hay

1 Llamas, Marta. «Usos, dificultades y posibilidades de la categoría género», Papeles de población, n 21,1999, pp. 147-178; Scott, Joan W. «Igualdad versus diferencia: los usos de la teoría postestructuralista», Debate Feminista, vol. 5, 1992, pp. 85-104. Scott, Joan W. «El género: una categoría útil para el análisis histórico, en Llamas, Marta. El género: la construcción cultural de la diferencia sexual, PEUG, México, 1996, pp. 265-308. Scott, Joan W. «El eco de la fantasía: la historia y la construcción de la identidad», Ayer, 2006, nº 62, pp. 111-138.

2 Tesis Doctoral: Rovetto Gonem, Florencia. La representación del trabajo de las mujeres en la prensa: Análisis comparativo y cualitativo de la información de actualidad, Departamento de Periodismo y de Ciencias de la Comunicación, Universidad de Barcelona, Bellatera, 2010; Sau Sánchez, Victoria. Diccionario Ideológico feminista, Icaria, 2000, pp. 45-47; Tesis Doctoral: Simelio Solá, Núria. Prensa de información general durante la transición política española (1974-1984): pervivencias y cambios en la representación de las relaciones sociales, Departament de Periodisme i de Ciències de la Comunicació, Facultat de Ciències de la Comunicació, Universitat Autónoma de Barcelona, 2006. 
que aproximarse a esta fuente para el «año 1975», todo ello a través de la disciplina histórica.

En este estudio no se pretende incidir ni profundizar en los usos o abusos del concepto género, ni en la influencia que dicha categoría ha tenido y tiene para los «estudios sobre/o de mujeres ${ }^{3} »$, pero sí es importante realizar una breve mención al mundo del «género», que conlleva profundizar en temáticas y cuestiones que habían pasado desapercibidas a los ojos del «hombre» o eran secundarias para su interés; conlleva el replantearse nuevos interrogantes y paradigmas científicos y académicos; y conlleva, finalmente visualizar las relaciones de «hombres y mujeres», «entre los hombres»y «entre las mujeres» desde una posición y actitud ante las mismas renovada.

Para el mundo académico, y concretamente desde la perspectiva histórica, los estudios de género y de mujeres han llegado a constituir una disciplina con carácter propio que presenta una gran riqueza, medida entre otros aspectos por su visión multidisciplinar. Una visión que este artículo pretende revelar al combinar el estudio histórico de las mujeres con el análisis de la fuente periodística. Una fuente que constituye una herramienta dinámica y rica para hacer Historia Comparada, con posibilidad de complementariedad con otras fuentes; y con una abanico de alternativas bastante amplio que da opción a jugar con la información que en ella se plasma. Pues no solo permite ver lo que se escribe y cómo es representada la sociedad a través de la prensa, sino que la sociedad puede representarse así misma de forma directa.

Pero cuando se trabaja con la prensa, a semejanza de la fuente oral, el filtro de la objetividad del historiador debe de estar posiblemente más al acecho de lo habitual, pues es a la vez un medio pero también un fin en sí

3 En la actualidad existen interesantes trabajos para aproximarse al sujeto de estudio en cuestión, véase, entre otros: Borderías, Cristina (eds). La Historia de las mujeres, Perspectivas actuales, Jería, Barcelona, 2009; Aguado, Ana. «La Historia de las mujeres como historia social», en $\mathrm{M}^{\mathrm{a}}$ Isabel del Valdivieso, Magdalena S. Tómas Peréz, $\mathrm{M}^{\mathrm{a}}$ Jesús Dueñas Cepeda, Cristina de la Rosa Cubo (eds), Universidad de Valladolid, 2004; Días Sánchez, Pilar. «Balance de los estudios sobre el trabajo de las mujeres en la España contemporánea», La Historia de las mujeres: una revisión historiográfica, en $\mathrm{M}^{\mathrm{a}}$ Isabel del Valdivieso, Magdalena S. Tómas Peréz, Ma Jesús Dueñas Cepeda, Cristina de la Rosa Cubo (eds): La Historia de las mujeres: una revisión historiográfica, Universidad de Valladolid, 2004; Hernández Sandoica, Elena. «Historia, historia de las mujeres e historia de las relaciones de género», en $\mathrm{M}^{\mathrm{a}}$ Isabel del Valdivieso, Magdalena S. Tómas Peréz, Ma Jesús Dueñas Cepeda, Cristina de la Rosa Cubo (eds), La Historia de las mujeres: una revisión historiográfica, Universidad de Valladolid, 2004. 
misma. Por consiguiente, transmite unos valores y una ideología ${ }^{4}$. Es un flujo de comunicación, de lenguaje entre las masas y el medio. Y como todo flujo de lenguaje o de palabras, éstas tienen una interpretación y un análisis que, insertadas en un discurso ${ }^{5}$, constituye una herramienta o fuente de valor esencial.

Actualmente los estudios e investigaciones sobre los medios de comunicación ${ }^{6}$ han recibido un considerable empuje tanto desde la perspectiva de género como desde la Historia Presente o Historia Actual. En este estudio se va a plasmar la imagen y el discurso sobre un tema específico, «El Año Internacional de la Mujer», imagen transmitida a través de los anuncios, viñetas, publicidad... que nos aproxima a unos esteriotipos ${ }^{7}$. El objetivo es mostrar cómo es representada dicha temática y «las mujeres» por los periodistas, cronistas, informadores... pero también recoger la opinión social del momento al respecto.

Otra faceta presente es el discurso ${ }^{8}$ : nos encontramos ante uno de los medios que transmite el poder, es una construcción y por consiguiente es una visión a tener muy en cuenta para entender y comprender el objeto

4 Van Dijk, Teun A. «Opiniones e ideologías en la prensa», Voces y culturas, 1996, n 10, pp. 9-50. Van Dijk, Teun A. «Análisis del discurso ideológico», en Versión, 1996, nº 6, pp. 15-43. 5 Van Dijk, Teun A. «Algunas notas sobre la ideología y la teoría del discurso», Semiosis, 1982, n 5, pp. 37-53. Van Dijk, Teun A. «El análisis crítico del discurso y el pensamiento social», Athenea Digital, 2002, n 1, pp. 18-24. Van Dijk, Teun A. «Discurso y dominación», en Grandes Conferencias en la Facultad de Ciencia Humanas, 2004, nº 4, Universidad Nacional de Colombia, pp. 5-28.

6 Algunos de los trabajos realizados a partir de la prensa: Arroyo Cabello, M. «Factores coadyuvantes al consenso periodístico en la transición (1975-1978)», Revista Latina de Comunicación Social, 2008, nº 63, pp. 1-21; Tesis Doctoral: Herrero Faúndez, Rocío. La imagen de la mujer en la prensa entre 1910-1915 y 2000-2005: Estudio Comparado, Madrid, 2010; QuirosaCheyrouze y Muñoz, Rafael. Prensa y Democracia. Los medios de comunicación en la transición, Biblioteca Nueva, 2009; Sesgado Boj, Francisco. «Un tópico perpetuado. La imagen de la mujer y el feminismo en el humor gráfico de la prensa diaria durante la transición (19741977), Zer (Revista de estudios de la Comunicación), 2009, vol. 14, nº 27, pp. 203-204.

7 Gallego, Juana (dir.). «La prensa diaria por dentro: mecanismos de transmisión de esteriotipos de género en la prensa de información general», Análisi, 2002, n 28, pp. 225242.

8 Foucault, Michel. El orden del discurso, Barcelona, Tusquets Editores, Buenos Aires, 1992. Para referirme al concepto «discurso» me remito a la funcionalidad dada por este autor: «En toda sociedad la producción del discurso es controlada, seleccionada, organizada y redistribuida por un cierto número de procedimientos que tienen la función de conjurar los poderes y los peligros, dotar el acontecimiento aleatorio, esquivar la pesada temible materialidad», p. 76. 
de estudio, pues ejercer el poder o el control sobre el discurso, palabras, símbolos, e imagen, permite representar e interpretar a los sujetos y los contextos. Así pues, controlando los medios que transmiten la información, se controla ésta y los fines que mediante ésta se pretende conseguir.

Un último motivo que justifica la elección de la prensa como fuente de estudio es su papel desempeñado en las etapas del Tardofranquismo y la Transición Española? ‘ ¿Pero, qué justifica la elección de un periódico concreto? ¿En base a qué premisas o criterios se establece la elección? En primer lugar indicar que hasta el momento hay una serie de publicaciones de ámbito nacional que ya han sido trabajabas, como son: La Vanguardia, El País, El Periódico de Catalunya, ABC, El mundo, La voz de Galicia, El ideal Gallego, El correo Español, El pueblo vasco, Cambio 16, Cuadernos para el Diálogo, El Alcázar, El Imparcial, Ya, El socialista... entre otros, así que, el diario de La Verdad de Murcia, se presentaba para este caso en particular como una fuente pendiente de análisis.

La Verdad de Murcia es un diario con un largo recorrido histórico, fue fundado en el año 1903 y en esa misma fecha saldría su primer número, el primero de una larga trayectoria que llega hasta nuestros días. Es un diario de publicación o tirada diaria, permitiendo realizar un seguimiento exhaustivo; además tiene considerable difusión, estando consolidado a nivel social e institucional; $y$, otro motivo para su elección, fue su carácter local o regional, con la finalidad de valorar qué se dice sobre las «mujeres» murcianas y su «Año Internacional de la Mujer» pero también cuál es la influencia nacional e internacional que se percibe en el mismo. Y finalmente, porque coincidiendo con el «Año Internacional de la Mujer», esta fuente fue nombrada Mejor Diario Español y Mejor Diario de Cobertura Regional ${ }^{10}$.

Un último aspecto a desarrollar en este apartado inicial es la temática: ¿Por qué el «Año Internacional de la Mujen»? ¿Por qué «1975»?. La celebración de esta conmemoración estuvo enmarcada dentro de un contexto internacional que influirá en el ámbito nacional. Para el caso español el escenario vino fijado por los intereses del propio régimen político, «La Dictadura Franquista», que desde las propias peculiaridades y matizaciones del sistema

9 Castro Torres, Carmen. La Prensa en la Transición Española, 1966-1978, Alianza, Madrid, 2010.

10 Archivo Municipal de Murcia (en adelante, AMM). La Verdad de Murcia, 26 de noviembre de 1975, p. 24. 
va a desarrollar este evento con características propias, que se analizarán en el siguiente apartado mediante el soporte periodístico. Desde el punto de vista político posiblemente el hecho que tuvo una mayor transcendencia, por sus posteriores repercusiones para el desarrollo de la Historia de España, fue «La muerte de Franco» el día 20 de noviembre. El país se encuentra en estas fechas inmerso en un proceso de transformación de las estructuras legislativas (ley 14/1975 sobre Reforma de determinados artículos del Código Civil y del Código de Comercio sobre la situación jurídica de la mujer casada y los derechos y deberes de los cónyuges ${ }^{11}$ ), laborales (incremento de la conflictividad sociolaboral), económicas..., así pues, el año 1975 es significativo por una multitud de motivos, incluyendo los de índole internacional, como la conmemoración del «Año Internacional de la Mujer». Tal fecha fue elegida por la Asamblea General de Naciones atendiendo a la resolución $3010^{12}$ de diciembre de 1972 sobre el «Año Internacional de la mujer, quedó así reconocido la celebración por el veinticinco aniversario del inicio de la Comisión Jurídica y Social de la Mujer, creada en 1946. Durante esa trayectoria se asentaron unas bases políticas y sociales de carácter internacional: Declaración de los Derechos Humanos (1948), Convención sobre los Derechos Políticos de la Mujer (1952), Convención Sobre la nacionalidad de la Mujer Casada (1957); Convención sobre el consentimiento para el matrimonio (1962) y Declaración de la Eliminación de la Discriminación contra la Mujer (1965). Medidas todas ellas que brillaron por su ausencia en la España del Franquismo, hasta la década de los setenta, como consecuencia de las circunstancias propias y generales del país, y por las relaciones con el exterior.

Respecto a «la mujer española», el contexto social del año 1975 era propicio para que las asociaciones, movimientos y organizaciones femeninas irrumpieran en el espacio público y político con paso firme. Además, viene definido por la creación del primer despacho de abogadas feministas, el «Colectivo Jurídico Feminista»; se creó «El Seminario Colectivo Feminista»; o se celebraron las Primeras Jornadas por la Liberación de la Mujen», que supusieron el reflejo de un duro, continuado y progresivo trabajo femenino realizado en ocasiones desde la clandestinidad por un conglomerado

11 Ley 14/1975 sobre la Reforma que determina dos artículos del Código Civil y del Código de Comercio sobre la situación jurídica de la mujer casada y los derechos y deberes de los cónyuges, Boletín Oficial del Estado, 5 de mayo de 1975, núm. 107, pp. 9413-9419.

12 Naciones Unidas. Resolución de la Asamblea General núm. 3010. Año Internacional de la mujer, XXVIII Periodo de Sesiones, 18 de diciembre de 1972, p. 73. 
polifacético de mujeres que obtuvieron con este acto una gran dimensión pública.

\section{El Caso español EN EL «AÑo INTERnacional de la MuJer»}

¿Qué organización representó a España en el Año Internacional de la Mujer? ¿Era la única opción? o ¿Era la única vía disponible para los intereses del sistema? ¿Y esa opción, representaba realmente a todo el conglomerado femenino? ¿Qué alternativas había? ¿Qué papel tuvieron? El Estado español sucumbió a la resolución 3010 de las Naciones Unidas y decidió intervenir en la conmemoración del «Año Internacional de la Mujer», para lo cual contaba de un brazo ejecutor propio, destinado a esas cuestiones, una herramienta de «mujeres» para «mujeres», pero dentro de los ejes y parámetros del sistema: «Sección Femenina».

Como se desprende de los estudios de Elena Díaz Silva ${ }^{13}$ y del diario de La Verdad de Murcia, la Sección Femenina vio en este acontecimiento la posibilidad para redimirse y adaptar el tradicional discurso de esta organización a las nuevas demandas femeninas. Así, introduciría sutiles modificaciones en su programa con el fin de poder perpetuarse en el tiempo. La apariencia de esta organización disipó un cierto reformismo en sus actuaciones, pero en lo concerniente a la actitud y pensamientos de las principales figuras femeninas, Pilar Primo de Rivera (dirigente a nivel nacional de Sección Femenina) y Carmen Verbo Sánchez (Delegada Provincial de Sección Femenina en Murcia), continuaban sosteniendo un ideario (algo suavizado) fundamentado en los pilares del nacional-catolicismo. Y teniendo presente el contexto social del momento (demandas femeninas para el mejoramiento de las condiciones de trabajo, reivindicaciones por la situación de insalubridad de los barrios, movilizaciones de madres y mujeres de presos, protesta por la subida de los precios en los alimentos...), caracterizado por la pluralidad y variedad en las de formas de organización y de dar respuesta a las demandas sociales, la Sección femenina introdujo modificaciones en sus prácticas como

13 Díaz Silva, Elena. «El Año Internacional de la Mujer en España: 1975», Cuadernos de Historia Contemporánea, 2009. Vol. 31, pp. 319-339. Díaz Silva, Elena. «El Año Internacional de la Mujer en perspectiva comparada: España y Francia. Un estudio comparado sobre la situación de las mujeres españolas y francesas hacia 1975», Seminario de Investigación, Departamento de Historia contemporánea, Universidad Complutense de Madrid, 2010, diciembre, pp. 1-18. 
medio de respuesta a la competencia «no oficial», y presentando una imagen renovada hacia el exterior en consonancia con las políticas internacionales.

El análisis del diario La Verdad, evidencia que esta actitud fue una cuestión de imagen. Por un lado se recoge la actividad que Sección Femenina organiza en conmemoración y como órgano oficial de «El Año Internacional de la Mujen, y desde otro punto, se observa como en las entrevistas a las figuras femeninas mencionadas con anterioridad, defienden los valores tradicionales. En esta institución aflora un problema de mentalidad y tradición, pues tanto Pilar Primo de Rivera como Carmen Verbo, son mujeres que pertenecen a esta organización desde sus orígenes y la tarea de actualizarse ante las circunstancias de 1975 requiere un doble esfuerzo: a la gesta de modernizar los pilares sobre los que se sustentaban se une la búsqueda de soluciones efectivas a las demandas femeninas. El fin buscado por Sección Femenina era constituirse como única vía factible para los problemas de «las mujeres» españolas.

Pero existen otras «opciones», otras «alternativas», además de Sección Femenina. Son organizaciones, asociaciones o movimientos que van a celebrar el «Año Internacional de la Mujer» desde una vía paralela a la oficial. Entre las organizaciones del momento (Asociación de Amas de Casa, Plataforma de Organizaciones de Mujeres de Madrid, Movimiento Democrático de Mujeres, Asociación de Mujeres Separadas, Acción Católica, Hermandad Obrera de Acción Católica...) encontramos un fértil y heterogéneo conglomerado: desde los grupos que siguen unos valores católicos semejantes a Sección Femenina, hasta los que apuestan por unas proposiciones más atrevidas y reivindicadoras. Está última posición para determinados sectores sería considerada de extrema o feminista pero contextualizadas en la situación mundial de la década de los 70 responde perfectamente a las demandas femeninas, no sólo de esposas o madres, sino de lo que significa «ser mujer» y obtener los mismos derechos y reconocimiento que los hombres. Los resultados del análisis del diario La Verdad permiten hablar de la existencia de «una conciencia femenina» que, coincidiendo con el «Año Internacional de la Mujen», genera un reagrupamiento de estos colectivos de mujeres, así como una mayor cohesión y coordinación entre ellos. Consideraban necesario solucionar tramas como la discriminación femenina, no sólo en el marco laboral sino en todos los ámbitos de la sociedad. Son grupos que se movieron en la línea de solucionar los problemas que realmente atañían a las mujeres, fomentando entre «ellas» una identidad y unos valores que transgredían el 
sistema franquista. El alcance y calado social de éstos dificultaron cualquier tarea del sistema por mantenerlos en silencio. Entre las cualidades a destacar, nos encontramos con la gran capacidad organizativa que tuvieron a nivel nacional, ejemplo de esto fue «la Plataforma de Organizaciones de Mujeres de Madrid», que creó su propio programa para la liberación de la mujer, denominado «Programa de las ONGs del Estado Español», que tenía como objetivo crear una organización de carácter unitario que englobaba a varios movimientos y asociaciones de mujeres, con el fin de asistir al Congreso Mundial de Mujeres que se celebraba en Berlín del 20 al 24 de Octubre de 1975. Esta organización asentó las bases para la plataforma y celebración, en diciembre de 1975, del I Congreso de Liberación de las Mujeres, donde se denunciaba:

La educación diferencial y de la doble moral, que marca pautas de comportamiento distintas para el hombre y la mujer desde su nacimiento, asi como la desaparición de la mujer como objeto sexual y su manipulación en los medios de comunicación ${ }^{14}$.

En algunos casos, estas asociaciones se encontraban vinculadas al Partido Comunista Español, como es el caso del Movimiento Democrático de Mujeres. Durante el año 1975, dicho partido ejerció un considerable activismo que confluyó en la convocatoria general a huelga de Madrid que finalmente no sería secundada mayoritariamente, ni por trabajadores ni empresarios, pero donde sí se constata la participación femenina. Además, las asociaciones femeninas, de mujeres, de amas de casa... se encargaron de denunciar la crisis económica que afectaba a los hogares españoles, la subida de precios, la insuficiencia de servicios sociales (guarderías, alumbrado...) y también reivindicaron los derechos de «las mujeres», como la libertad y los valores democráticos. Como nos indica Mónica Threlfall:

La acumulación de muchas pequeñas actuaciones, que por si solas no tuvieron quizás un gran impacto pero que, tomadas en su conjunto, crean una narrativa que demuestran la activa participación de mujeres organizadas ${ }^{15}$.

14 «Resoluciones y conclusiones de las I Jornadas por la liberación de la mujer», Madrid, 1975, pp. 147-150, en http://www.amparomorenosarda.es/en/node/88. (consultado 18 de enero de 2012).

15 Threlfall, Mónica. «El papel transformador del movimiento de mujeres en la transición política española», en Martínez Ten, C, Gutiérrez López, P. y González Ruiz (eds): El movimiento feminista en la España de los años 70, Fundación Pablo Iglesias, Edición Catedrá, Instituto de la Mujer, 2009, p. 30. 
Cuando finaliza el año 1975 nos encontramos con unas fuerzas femeninas organizadas y preparadas para actuar y participar activamente en la vida social española a partir de esas fechas y durante el proceso de Transición a la Democracia, mientras que la Sección Femenina vería como en el año 1977, por el Real Decreto-Ley 23/1977 ${ }^{16}$, sus días estaban contados.

\section{El «AÑo Internacional de LA MUJER» EN PAPEL}

El objetivo de este apartado del artículo es presentar y mostrar cómo mediante el análisis del diario La Verdad de Murcia nos aproximamos a la imagen y al discurso que se plasmó sobre esta conmemoración, evidenciar qué representatividad tuvó para la sociedad y cómo se transmitió en este medio, a través de qué noticias y en qué términos. El volumen de artículos y noticias analizadas y contabilizadas en referencia al concepto o término «mujer» para el año 1975 en el diario La Verdad de Murcia asciende al computo de 1.499, de los que 79 se ciñen a la temática propuesta. Una mejor idea de lo que estas cifras suponen se representa en la siguiente gráfica:

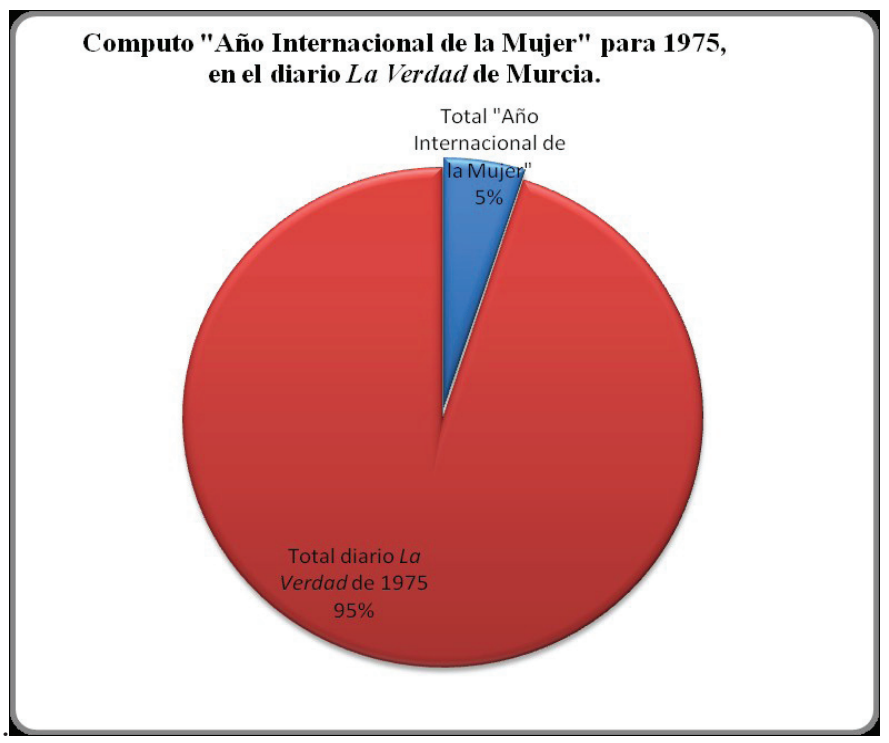

Figura I. Elaboración propia

16 Real Decreto-Ley 23/1977, de 1 de abril sobre reestructuración de los Órganos dependientes del Consejo Nacional y nuevo régimen jurídico de las Asociaciones, funcionarios y Patrimonio del Movimiento, Boletín Oficial del Estado, de 7 de abril de 1977. 
Como se puede visualizar, la información recogida en este medio periodístico concerniente al «Año Internacional de la Mujen» constituye un 5\% del total. Cifra que lleva a plantearse dos cuestiones: la primera que, la temática trabajada fue recogida por la fuente en un intento de representar los intereses que la sociedad pudiese tener al respecto; y en segundo lugar, se evidencia que no se le dio la difusión y propaganda que dicho evento requería o que se buscaba desde Naciones Unidas.

En la siguiente gráfica se observa que la evolución mensual sobre «El Año Internacional de la Mujer», que se reparte de forma dispar. Pero tan importante es tener una visualización cuantitativa de los datos como cualitativa, por lo que procedo al análisis de los contenidos e información que nos desvela la fuente.

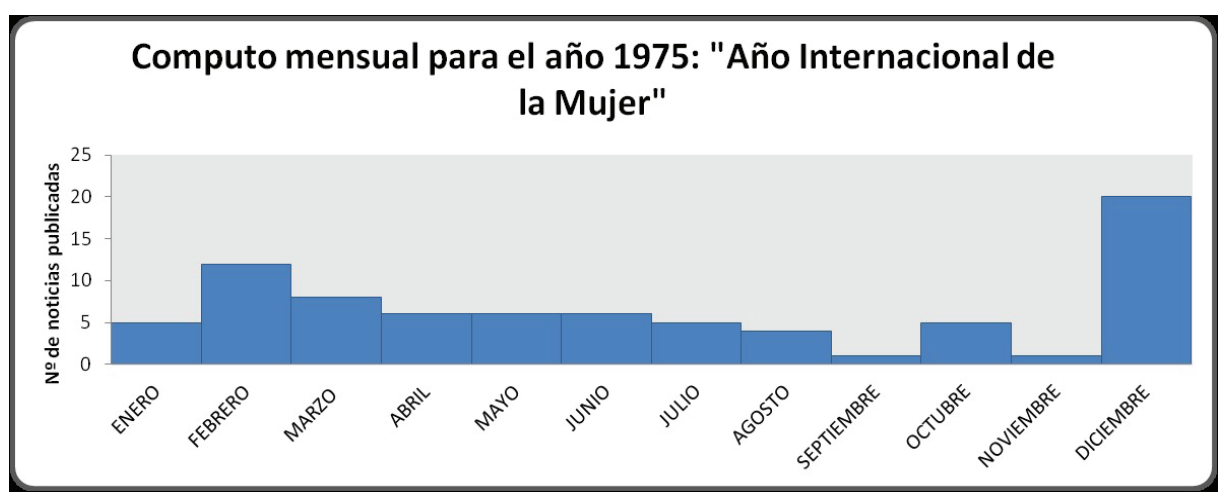

Figura II. Elaboración propia.

Si observamos la gráfica se distingue en primera instancia que el mes de diciembre despunta por el mayor número de referencias. Para entender esta mayor plasmación de la temática en el medio es necesario tener presente un par de acontecimientos. El primero que puede destacarse es el fallecimiento de Franco el 20 de noviembre de ese año, que además permite explicar la poca evidencia informativa sobre «la cuestión de la mujer» en este mes, se dedicó a la evolución de la enfermedad del caudillo y su posterior fallecimiento. Pero el mes de diciembre adquirió un carácter más activo, estimulado por el cierre del año y la recapitulación de las actividades organizadas durante el mismo, adquiriendo un papel fundamental las valoraciones que se realizan sobre el mismo.

Entre las opiniones recopiladas en torno a la celebración del «Año Internacional de la Mujer» nos encontramos con varias perspectivas: 
aquellas/os que consideran el evento ridículo, alegando que esta celebración pone de relieve la situación discriminatoria en la que se encuentra la mujer, la vincula con los grupos marginados o los insuficientes resultados que se obtendrán al respecto; al otro lado de la balanza, las voces que opinan con optimismo, defendiendo que esta conmemoración no solucionará todos los problemas, pero si serviría para mentalizarse sobre los mismos. Una tercera opinión muestra cierta pasividad como consecuencia de la falta información. Para ejemplificar el primero de los casos he acudido al escrito de Conchita Reyes $^{17}$, ElMejor Titulo, que dice al respecto:

Por fin acaba el año y con él ese título tan poco afortunado de «Año Internacional de la Mujen». Este tema ha sido tocado con más o menos seriedad, pues más parece tratarse de un slogan publicitario que de algo tan serio como de un ser bumano ${ }^{18}$.

Hay opiniones que comparten una visión semejante a la presentada que ven en la celebración de dicho evento un símbolo que reconoce la inferioridad de la mujer. Esta conmemoración se visualiza como un problema de los países subdesarrollados y, por consiguiente, España, como desde esta opinión personal no está catalogado de «subdesarrollado», no necesita o precisa profundizar en dicha cuestión. Pero la realidad de la situación de las mujeres se evidencia en las reclamaciones que éstas realizan públicamente al margen de los parámetros del sistema. Esas pretensiones muestran el trabajo pendiente respecto a derechos y discriminación entre hombres y mujeres. Además, poniendo entre dicho las palabras de la entrevistada, se puede considerar que las políticas de género y sobre la discriminación femenina son en aquellas fechas como en la actualidad de vital importancia, tanto en países «desarrollados» como «subdesarrollados», independientemente de esta catalogación, pues las cuestiones de «mujeres» están presente a nivel internacional, ya que éste sexo constituye «la otra» mitad de la población mundial. Ejemplos como el expuesto muestra los procesos culturales y de las mentalidades en las sociedades.

Esta primera perspectiva femenina es la más conservadora, pero progresivamente se podrá apreciar, en las siguientes intervenciones, cómo las opiniones adquieren otro semblante, cada vez más moderno y abierto.

17 Conchita Reyes de Navarro Porlán, escritora que publicó números y sugerentes artículos en la prensa periódica de Murcia (La Verdad, Linea, Hoja del lunes, La Opinión).

18 AMM. La Verdad de Murcia, 3 de diciembre de 1975, p. 10. 
En este primer caso destacar el lenguaje utilizado por su autora, tanto para referirse a la mujer (capaz solamente de fijarse en nimiedades) y al hombre; cómo en los adjetivos utilizados para referirse al «año internacional de la mujer» (por ejemplo: ridículo) o cuando se refiere al concepto de igualdad (dice así: «en principio creo que la mujer posee la misma capacidad cerebral que el hombre, pero ahí termina su igualdad»).

Un segundo bloque de noticias analizadas muestra el importante protagonismo que tienen las asociaciones y organización católicas, lo cual viene definido por la propia personalidad del diario, de ideología católica. Así pues, encontramos la autoría del reverendo Juan Hernández, la presencia notable de artículos de asociaciones como Acción Católica o HOAC, o defensa de los valores católicos... que se traduce en noticias como las Conferencias organizadas en el mes de diciembre por los Movimientos de Apostado Seglar de la Diócesis ${ }^{19}$.

Las entrevistas, noticias... permiten apreciar un cambio generacional femenino, pues la percepción sobre las «mujeres» que emanan de los diferentes discursos muestran una gran diversidad de posiciones al respecto. Una de las entrevistas realizadas por el reverendo Juan Hernández fue a Pilar Crespo $^{20}$ con motivo de su conferencia por el «Año Internacional de la Mujer» en Murcia, de la que destacó: su cariz católico no solo en lo referente a la Iglesia o sociedad, sino del papel de la mujer, pero donde aboga por la compatibilidad entre el trabajo en el hogar y fuera del mismo. En su propuesta el problema que manifiesta es la promoción de la mujer en la vida laboral, pues según declara la entrevistada, la cuestión que subyace en el fondo es que la promoción femenina conlleva el abandono de las obligaciones y responsabilidades femeninas con el hogar ${ }^{21}$. Una cuestión

19 Nicolás Marín, Mª Encarna y López García, Basilisa. «La situación de la mujer a través de los movimientos de apostolado seglar: la contribución a la legitimación del franquismo (1939-1956)», en Durán, $M^{a}$ Ángeles y Capel Martínez, Rosa $M^{a}$ (autoras): Mujer y sociedad en España (1700-1975), 1986, pp. 365-390. López García, Basilisa. «Discrepancias y enfrentamientos entre el estado franquista y las asociaciones obreras católicas», Anales de Historia Contemporánea, 1986, Universidad de Murcia, Vol. 5, pp. 177-187.

20 Pilar Crespo de Arillo fue redactora jefe del Secretariado Diocesano de Medios de Comunicación Social de Zaragoza, miembro de la Comisión Nacional de Acción Católica. 21 AMM. La Verdad de Murcia, 6 de diciembre de 1975, p. 6. Pilar Crespo de Arillo, dice: «Suele confundirse 'promoción' con 'trabajo' de la mujer. El término 'promoción' es mucho más amplio que el de trabajo, sin otros calificativos. No existe oposición entre ambas dedicaciones de la mujer, porque no son excluyentes. La mujer para alcanzar un puesto de responsabilidad de la vida social, cultural, política, etc, ni por trabajar, es menos mujer. (...) 
que pervive en nuestra sociedad actual, con el matiz de que en el año 1975 se comenzaba hablar de paridad y, en el año 2012, trabajamos para que se convierta en una realidad.

El discurso de Pilar Crespo estaba más en sintonía con los movimientos femeninos de la década de los setenta que con los valores del sistema, pero es verdad que en su intervención no se plantean cuestiones como el aborto, para los cuales dicha figura y desde su ideología católica posiblemente defendería una postura más tradicionalista y conservadora. Para el año 1975 las temáticas que básicamente se trataban en estas conferencias se relacionaban con el ámbito laboral y la discriminación de la mujer en éste. Por consiguiente, al estudiar esta información siempre habrá que plantearse quién es el organizador; quién interviene y desde que postura; y cuál es su mensaje y en qué materias se vincula con su organización.

En línea con Pilar Crespo se encuentra la opinión de Pilar Bellosillo ${ }^{22}$ en el artículo escrito por José Saura Hidalgo ${ }^{23}$ : Año Internacional de la Mujer: El hombre tiene que descubrir todo lo positivo que traen estos cambios ${ }^{24}$. Entre las cuestiones que se pueden destacar, habla de valores del mundo masculino y valores del mundo femenino, pues durante siglos es así como se ha dividido los espacios, quedando en el limbo un conglomerado de grupos sin determinar. Pero el que exista un sistema de valores femeninos no quiere decir que estuviese en igualdad o paridad de condiciones que el masculino, pues a pesar de su reconocimiento estaba más identificado y vinculado a los «marginados». Este marco lleva a plantearse si todas las mujeres estaban incluidas en ese «sistema de valores de mujeres», porque ese sistema no es reflejo de la realidad femenina ya que hay mujeres que estaban y están

Yo aprovecharía esta ocasión para decir que es hora de que despierte la conciencia, un tanto dormida de la mujer, en orden a su incorporación a la tarea de edificar nuestro mundo, nuestra sociedad. Y de que la sociedad reconozca los derechos, valores y condiciones de la mujer en paridad con los hombres».

22 Pilar Bellosillo era miembro del Consejo de la Unión Mundial de Organizaciones Femeninas Católicas y del Grupo Mixto de Trabajo entre la Iglesia Católica y el Consejo Mundial de las Iglesias.

23 José Saura Hidalgo nacido en Cartagena (Murcia) fue redactor de prensa y escritor. Publicó en La Verdad, El noticiero de Cartagena, Arriba, Linea, Melilla, en el semanario Hoja del Lunes entre otros. Además fue presidente-fundador de la Asociación Amigos de las Bellas Artes y las Letras, y dirigió la revista anual ÄBAL. Para más información consultar: http:// richardsaura.blogspot.com/2011/03/desde-mi-molino-recordando-josahi-en-su. html. (consultado 17 de enero de 2012).

24 AMM. La Verdad de Murcia, 17 de diciembre de 1975, p. 6. 
discriminadas dentro de ese sistema, por lo que son marginadas atendiendo a este modelo de «mujer» y por ser «mujeres». Dentro de este sistema alternativo encontraríamos a las «mujeres de los medios rurales», que para la entrevistada sería unos de los focos sobre los que habría que trabajar en pro de la promoción.

$\mathrm{Si}$ atendemos a los planteamientos realizados por «las mujeres» entrevistadas en este diario sobre «mujeres» se puede encontrar una dicotomía al respecto. Mientras que se defiende que en España este «Año Internacional de la Mujer» puede resultar innecesario, pues no hay grandes tareas por desarrollar, desde otra vertiente son las propias mujeres de unos determinados círculos que, desde la «otredad», nos hablan de la «alteridad» que dentro de ellas existe, que evidencia las deficiencias ocasionadas por el sistema para llegar al reconocimiento de la igualdad entre hombres y mujeres, y actuar y funcionar en paridad ${ }^{25}$.

La conclusión que resulta de los posicionamientos en los escritos de las mujeres analizados a través de esta fuente, que defienden un prototipo y valores de «mujer» que hasta el momento no se había posibilitado, suponen una ruptura respecto al modelo «cerrado» creado y difundido por el régimen franquista. Se fractura el arquetipo de mujer como «ángel del hogan», como hija, esposa y madre del sistema patriarcal. Pero, por otro lado, ciñen su cambios a ámbitos muy específicos, sin llegar a plantearse o cuestionarse cuáles serían las auténticas consecuencias que desde ese momento se produciría en lo que se concebía como «ser mujer» y en su relación con aquellas «otras» mujeres que no están en el mismo «sistema de valores»y los hombres. El abanico que se abre a partir de estos momentos abarcaría cuestiones, opciones y posibilidades, así como reclamaciones y demandas de «las mujeres» que en las conferencias organizadas por las asociaciones

25 Cuando hablamos de «igualdad» nos referimos a un derecho natural del individuo al igual que la «libertad», pero la «paridad» que va ligado al concepto de «igualdad», en palabras de Rosa Cobo «no sería un principio -el principio como horizonte regulativo sería la universalidad- sino una estrategia orientada a ampliar la libertad, la igualdad y la autonomía de las mujeres en las sociedades patriarcalmente estratificadas. La paridad pues se inscribiría en las políticas de igualdad». Para más información consultar Cobo, Rosa. «Democracia paritaria y sujeto político feminista», en Anales de la Cátedra de Francisco Suárez, 2002, nº. 36, p. 38. Este documento está disponible en línea: http://www.ugr.es/ filode/pdf/conte nido36_2.pdf ; y Villanueva, Rocío. «Universalidad, igualdad y paridad. Las mujeres latinoamericanas en los poderes del Estado», Declaración de Atenas, pp. 1-5. Disponible en línea: http://www.eclac. $\mathrm{cl} /$ mujer/noticas/paginas/2/28422/ PonenciaRoc\%C3\%aDoVillanueva.pdf. (consultado 17 de enero de 2012). 
de corte católico no ocupan lugar ni son previstas. En conjunto, todas estas voces femeninas católicas realizan aportaciones muy interesantes y coherentes entre las relaciones de hombres y mujeres; y qué supone el «Año Internacional de la Mujer» para Acción Católica, así como los fines que se pretenden conseguir. Estas mujeres crearon su propio discurso sobre las relaciones de género y su modelo de mujer desde la década de los sesent. ${ }^{26}$.

Una última visión femenina entre las muchas que se dan durante el año 1975 por el «Año Internacional de la Mujer, es la proporcionada por Josefina Carabias ${ }^{27}$, en un artículo titulado El Extraño Capricho. El problema que plantea nuestra escritora es la reticencia de los maridos al trabajo de las mujeres fuera del hogar. Para explicar esta actitud hay que dirigir la mirada a la legislación sobre la que se ampara el Régimen Franquista, enfocada a inculcar los valores del nacionalcatolicismo y del tradicional sistema del patriarcado. Estos fines explican las medidas adoptadas nivel legislativo (como las natalistas y proteccionistas hacia la familia tradicional; leyes laborales que relegaban a la mujer al hogar, limitándola al ámbito de lo doméstico y de privado) y educacional (para lo que se apoyó en Sección Femenina y Acción Católica). El punto que plantea nuestra autora en su entrevista a otra mujer, madre y esposa, se resume en estas líneas:

A ver si con esto del Año Internacional se consigue que las cosas cambien. iQue nuestros maridos aprendan de sus hijos! Es verdad que éstos a veces, nos dan bastantes disgustos. Pero también dan-sobre todo al padre-muy buenas leccione. ${ }^{28}$.

La idea es que el hombre debe de introducirse e involucrarse en el hogar, no solo con la esposa, sino con los hijos, trabajando los lazos de la paternidad. Plantea una problemática que podemos trasladar a nuestra Historia Presente, y es la fatal de conexión entre hombres y mujeres para

26 Moreno Seco, Mónica. «De la Caridad al Compromiso: Las mujeres de Acción Católica (1958-1968)», Historia Contemporánea, 2003, no 26, pp. 239-265. En este artículo la autora expone sobre el proyecto de Acción Católica de Mujeres: «En su discurso hacia las mujeres españolas, abandonó el prototipo femenino de la posguerra, encerrada en casa y de una rígida moralidad, para ofrecer una adaptación a una realidad social en proceso de cambio», p. 247.

27 Josefina Carabias considerada una de las mujeres pioneras en el mundo del Periodismo español, sus trabajos son tratados de forma crítica y periodística. Actualmente es reconocida como una de las mujeres que luchó a favor del feminismo y por la consecución de la igualdad.

28 AMM. La Verdad de Murcia, 27 de febrero de 1975, p. 2. 
interrelacionar los espacios, siendo el primero el que establece las principales limitaciones para que se produzca ese entendimiento. Si bien es verdad que en este siglo XXI se han dado importantes pasos y, teóricamente, las personas comprendemos la importancia de establecer relaciones y espacios en común desde la paridad. En la práctica no resulta tan simple pues como se disipa en la información presentada por Josefina Carabias, el peso del hombre continúa siendo mayor en la actividades de ámbito público que en aquellas relacionadas con las domesticidad e incluso con los hijos, pues dentro del modelo tradicional el vínculo que siempre se ha fomentado ha sido la maternidad y además se ha planteado como una tarea o un trabajo propiamente asignado a la mujer. Por consiguiente, si la inserción femenina es fomentada y planteada desde la política, con el fin de que se introduzca en los mismos espacios que el hombre, se requiere que éste, paritariamente, se incorpore o involucre en las actividades reservadas a las mujeres, pues aunque la mujer parta de tener las características biológicas propicias para la fecundación de otro ser vivo, existe otro tipo de experiencias, como las culturales, que deben de fomentarse, tanto desde la maternidad como de la paternidad, y es en este tipo de acciones sobre las que debe de trabajarse paritariamente.

En definitiva, cuando la escritora se refiere al «extraño capricho», nuestro capricho sería la necesidad personal de las mujeres como tales de trabajar fuera del hogar, independientemente del status social o situación económica, pues no sería exclusivamente por dinero, sino por la autorrealización de la persona. Como expresa nuestra autora: «esas mujeres que aparentemente lo tienen todo, las que no se conforman con hacer papel de objeto de lujo social o damas de compañía. Muchos no comprenden aún ese «extraño capricho». El hombre no entiende y no comparte el valor o el significado que para «la mujer» y para el constructo de «ser mujer» alcanza el trabajo laboral, el realizarse como persona e individuo al igual que el hombre en un medio que no se ciñe a las tareas domésticas, pues les da opción de relacionarse con otras mujeres, compartir sus experiencias, generar lazos de amistad o sororidad $^{29} \ldots$ e incluso una conciencia colectiva. Una conciencia que estaba

29 Lagarde, Marcela: «La política feminista de la sororidad», en La Carta de las Mujeres a la Humanidad, 2009, en http://singenerodedudas.com/tirnamban/1154/la-politica-feministade-la-sororidad (consultado 31 de julio de 2010). El concepto sororidad aparece reflejado en obras de Emilia Pardo Bazán, fructífera escritora del siglo XIX y cuya obra a destacar para este concepto es «El Revolven», un breve cuento donde la autora realiza un formidable trabajo caracterizado por el realismo de su narración, de sus diálogos, del contexto... y por 
sustentada en la puesta en común de sus problemas individuales y de grupo, y que convergían en la búsqueda de soluciones y de propuestas, pero desde la perspectiva femenina.

Hay más elementos, además del trabajo extradoméstico, que permiten u otorgan a las mujeres adquirir autonomía e independencia respecto al «hombre». Entre las opciones posibles, se recoge de forma muy específica en La Verdad: la capacidad de la mujer de conducir ${ }^{30}$, pues el coche es presentado como elemento de liberación, que otorga la movilidad no solo de los hombres sino de las mujeres para trabajar, realizar actividades, etc, pero en el segundo caso, con el incipiente de no depender de la «otra» persona para ello, que es lo que había sucedido masivamente hasta la fecha. No obstante, no debemos de olvidar que frases como «mujer al volante, peligro constante», que llegan hasta nuestra actualidad y que fundamentalmente son planteadas desde una retrógrada y humillante masculinidad, intentan evidenciar la falta de destreza e inferioridad femenina en la conducción.

Hasta el momento se ha mostrado qué opinan ciertas figuras femeninas sobre su año, pero el «sexo masculino», ¿Qué valoración da al respecto? Entre las primeras opiniones del año 1975, destacan el Profesor Yela ${ }^{31}$, que muestra una perspectiva sensata, progresista y objetiva en lo referente a «la mujer». Su perspectiva se evidencia en frases como «la auténtica meta parece estar en la razonable colaboración de varón y mujer en todos los terrenos», o «las mayores urgencias se localizan, sin duda, en una corrección de las desigualdades jurídicas y en un cambio de mentalidad de los varones y también de un buen número de mujeres» ${ }^{32}$. Yela presenta un pensamiento realista, pues asume que la cuestión entre hombres y mujeres es de los dos, y que requieren de ciertas transformaciones y medidas, no solo a nivel legislativo sino «cultural», pues sin duda «la cultura» ejerce un gran

la importancia del tema en cuestión, la violencia hacia la mujer.

30 AMM. La Verdad de Murcia, 7 de octubre de 1975, p. 4.

31 Mariano Yela (1921-1994), fue Doctor en Filosofía por la Universidad de Madrid, miembro del Instituto Luis Vives de Filosofía, del Consejo Superior de Investigaciones Científicas, Cofundador del Departamento de Psicología Experimental del Consejo Superior de Investigaciones Científicas y organizador del mismo en 1948, miembro fundador de la Sociedad Española de Psicología y Secretario de las misma desde su fundación en 1952 hasta 1958, Director del Departamento de Psicología Experimental de la Facultad de Filosofía y Letras (Universidad Complutense de Madrid 1975), entre otros muchos cargos hasta el año 1994. Para más información: http://www.ucm.es/info/pssocial/carlosyela/ cvmyg.htm (consultado 18 de enero de 2012).

32 AMM. La Verdad de Murcia, 26 de enero de 2012, p. 2. 
poder desde el momento en que se utiliza como medio para naturalizar comportamientos sociales que, por ejercerse de una determinada forma, en un momento concreto, no significa de que hayan sido así siempre. Así por ejemplo, la mujer siempre ha trabajado al igual que el hombre, sin embargo se le ha dado una relevancia menor e inferior, utilizando entre los motivos justificantes, la fuerza física y violencia psicomática, por todo lo demás, como dice el profesor Yela, «el mito de la mujer (...) contiene muchas falsedades».

Como propuesta alternativa a esta perspectiva o visión de la cuestión de hombres y mujeres, el artículo del teólogo agustino P. César Vaca ${ }^{33}$, recogido en el diario La Verdad bajo el título de Justicia en el Año de la Mujer ${ }^{34}$, donde se aparecen frases como: «Si la igualdad se refiere a una misma consideración de ambos en cuanto personas humanas, debe aceptarse sin regateos. Si se entiende la igualdad a todo los niveles, no me parece justo (...)»o «Un intento de mero igualitarismo supondría una deformación de la mujer, al obligarla a introducirse en unos moldes no hechos para su condición femenina». Estas frases nos acercan claramente a la postura y defensa realizada por el P. César Vaca. Se sustenta en un ideario que defiende el estereotipo y rol femenino tradicional, donde «la mujer» es concebida como un ser inferior y más débil, que necesita protección. Esta definición o caracterización nos recuerda a los humanistas y moralistas de época moderna, como el discurso de Fray Luis de León y su «Perfecta Casada», entre los numerables ejemplos que fomentaron el arte de la escritura para el disciplinamiento femenino.

Otro aspecto de este artículo es el reconocimiento, por el autor de que «las leyes existentes en todos los códigos del mundo están hechas por varones», aquí subyace una parte del problema, la invisibilidad de la «mujen», de las «mujeres», en la Historia, a las que no se les permitió participar en ésta de forma activa. Es verdad que podemos hablar de «grandes mujeres de la Historia» pero, ¿es que a caso no somos todas las mujeres parte de esa Historia? Entre las transformaciones, cambios, avances... que podemos destacar desde el año 1975 hasta nuestro año 2012, es que dicha afirmación

33 César Vaca, teólogo agustino perteneciente a la Orden de San Agustín que publico para el periódico Ya de Madrid y escribió obras como: Haz meditación (1952), La castidad y otros temas espirituales (1956), Ensayos de psicología religiosa (1958), Psicoanálisis y dirección espiritual (1960), Guias de almas (1961), La Vida religiosa en San Agustin (1962), El espiritu y la libertad: conferencia pronunciada en la Fundación Universitaria Española el 16 de noviembre de 1977(1978), entre otras.

34 AMM. La Verdad de Murcia, 16 de febrero de 1975, p. 2. 
no es válida para nuestro tiempo, pues tanto hombres como mujeres intervienen de forma activa en dichas tareas.

¿Qué opinan los políticos respecto al «Año Internacional de la Mujer»? Para aproximarnos a esa visión he seleccionado unas palabras de Carlos Arias Navarro ${ }^{35}$ (Presidente del Gobierno en esos momentos) con motivo de la inauguración de dicha conmemoración: «La preocupación por la igualdad de oportunidades entre el hombre y la mujer es una consecuencia inevitable de otros fenómenos que se vienen registrando en el seno de la sociedad industrial desde hace por lo menos un siglo» ${ }^{36}$. En estas líneas el Presidente del Gobierno presenta un gran formalismo al respecto, posiblemente, la expresión sobre la que se pueda matizar es «igualdad de oportunidades», pues la realidad femenina española no solo demandaba reformas y cambios en trabajo o educación, sino una transformación a niveles más profundos de la sociedad. Es en esta idea donde se percibe el reflejo de la política del régimen y hacia qué parámetros se dirige. Realmente se plantean modificaciones en las estructuras del sistema, pero insuficientes para responder a los cambios que se fraguaban.

Otro concepto o alusión utilizada por Arias Navarro es «sociedad industrial», sin duda, una categoría que daría lugar a un estudio por sí misma. Pero la cuestión a tratar es su inserción dentro de este discurso, pues cataloga y califica a España y su sociedad de industrializados Para el caso español, estas palabras nos indica que era un proceso iniciado pero pendiente de concluir, donde la sociedad se encontraba inmersa dentro de los ciclos de cambios y transformaciones que van enraizado al mismo, y donde «las mujeres» tienen predefinida su función no solo en el ámbito doméstico sino constituyendo una fuente de mano de obra ${ }^{37}$.

En definitiva, la postura discursiva que muestran los representantes del Estado, como Arias Navarro, a los medios de comunicación y desde éstos,

35 Carlos Arias Navarro (1908-1989), fue político español ligado al régimen del general Franco y entre los cargos ostentados: alcalde de Madrid, desde 1965. En el gobierno de Carrero Blanco entró como ministro de Gobernación en 1973, y desde el año 1974 ocuparía la Jefatura del gobierno, tres el atentado terrorista sufrido por Carrero. Para más información: http://www.biografiasyvidas.com/biografia/a/ariasnavarro. (consultado 17 de enero de 2012).

36 AMM. La Verdad de Murcia, 20 de febrero de 1975, p. 13.

37 Valiente Fernández, Celia: «La realización del régimen franquista: la Ley de 22 de julio de 1961 sobre derechos políticos, profesionales y de trabajo de la mujer», en Historia Social, 1998, no 31, pp. 45-65. 
es de receptividad ante los problemas de las mujeres de la sociedad española. Pero esta perspectiva transmitida con motivo del «Año Internacional de la Mujer», es una falacia en la práctica. Las soluciones adoptadas estuvieron encauzadas a la protección de la superestructura que englobaba la dictadura. Por ello, se adoptarían las medidas oportunas contra las asociaciones femeninas que no funcionaban encauzadas en esas línea. ${ }^{38}$.

¿Cuál es la transcendencia de este «Año Internacional de la Mujer»? Para conocer y transmitir la función de esta celebración, recopilo la actividad recogida del diario La Verdad de Murcia en los siguientes campos ${ }^{39}$ :

1. Mejoras legislativas (el proyecto de Ley de Relaciones Laborales, donde se recoge la plena capacidad laboral de la mujer).

2. Declaraciones de las organizaciones católicas en pro de la igualdad entre hombres y mujeres en los ámbitos «laborales» y «educacionales», así como, eliminar la consideración de la mujer como una menor de edad.

3. Realización de estudios sociológicos, actividades y cursos para fomentar la participación femenina en tareas masculinas (curso de tractoristas femenino). Respecto al estudio sociológico, destacar que se realiza con el fin de resaltar aquellos atributos que deben de definir a «las mujeres».

4. Notificación de la promoción de «mujeres» en el ámbito laboral (como el juramento del cargo de abogado de una mujer murciana), y en algunas ocasiones, esa actuación femenina vendrá precedida por la figura del marido, manteniendo esa sombra de la mujer como hija, esposa y madre, es decir, «ser mujen» en función del vínculo con el hombre.

38 AMM. La Verdad de Murcia, 26 de febrero de 1975, p. 11.

39 A continuación, se detalla los artículos que justifican la división en dichos campos temáticos: AMM. La Verdad de Murcia, 26 de enero de 1975, p. 2; 31 de enero de 1975, pp. 9-10; 22 de febrero de 1975, p. 9; 28 de febrero de 1975, p. 2; 1 de marzo de 1975, p. 3; 12 de marzo de 1975, p. 10; 16 de marzo de 1975, p. 3; 3 de abril de 1975, p. 7; 25 de abril de 1975, p.p. 2 y 13; 16 de mayo de 1975, p. 5; 23 de mayo de 1975, p. 6; 5 de junio de 1975, p. 14; 21 de junio de 1975, p. 21; 26 de junio de 1975, p. 18; 1 de julio de 1975, p. $30 ; 5$ de julio de 1975, p. 13; 11 de julio de 1975, p. 18. 
5. Participación de las mujeres en deportes y actividades masculinas (como el caso de Lolita García, primera española de lucha libre, o la organización de corridas de Toros con rejoneadoras y toreras).

6. Conferencias, Congresos y mesas redondas con temáticas como «la mujer y el trabajo», «mujer y familia», así como la construcción del primer centro de Educación Maternal de la Región de Murcia, que perpetuaba la labor realizada con motivo de esa celebración.

7. Opiniones de mujeres como Betty Friedan, catalogada de «revolucionaria», o la controversia generada por Esther Vilar en torno a su libro El varón polígamo. Entre las consecuencias de este año estuvo el aumento de publicaciones femeninas y la mayor plasmación de información sobre las mismas en los medios, generando una vía de desarrollo y de transmisión para el feminismo.

8. En el diario La Verdad se introduce, en el diseño con motivo de la celebración del «Año Internacional de la Mujer», un apartado en sus páginas bajo esta denominación, lo cual demuestra y evidencia que se intentaba dar en la práctica, difusión a esta conmemoración.

9. Entre las temáticas publicadas en la fuente hemerográfica analizada se incide en la cuestión de la discriminación sexual. Dos artículos de Juana García de Jorquera se centran en esta cuestión y explica los fundamentos utilizados desde la masculinidad para excluir a las mujeres a determinados espacios dentro de la sociedad. En sus líneas utiliza la evolución de los seres humanos para explicar lo maleable que puede resultar el pensamiento y cómo se forja en función de unos intereses. También incide en la cuestión de cómo acabar con la discriminación, para lo cual defiende que no se debe de favorecer a la mujer por el hecho de serlo, sino que debe de ser tratada en igualdad de actitudes que un hombre. Los trabajos presentados por esta escritora muestran una perspectiva muy interesante pero, posiblemente, muy pocas mujeres de su tiempo se situarían en ese grado de progresismo.

10. Intervenciones públicas de altos cargos de Sección Femenina, donde se apuesta por un discurso que compagine tradición con propuestas de trabajo y fomento de la participación femenina en los 
cursos, actividades... destinadas a ellas, con el fin de, culturalmente, estén mejor preparadas.

La información de las noticias y artículos del año 1975 de La Verdad de Murcia barajada en este trabajo solo constituye un 5\%. Sin embargo, el tipo de fuente contribuye a situarse ante una documentación rica y variada que posibilita una heterogénea combinación para la recopilación, estudio y análisis de la misma. Así pues, los puntos temáticos presentados, sona grosso modo un ejemplo entre las distintas opciones viables. Destaca la figura masculina como trasmisor de la información en este diario, mientras que la presencia femenina se enfoca más a ser la noticia, la entrevistada... y, aunque su participación sea menor, puede apreciarse la relevancia de estas mujeres, que constituyeron en aquellos momentos las voces femeninas, independientemente de su posición ideológica. Lo destacable en sí es que las mujeres tuviesen opción a opinar, comentar y escribir, no solo en revistas catalogadas propiamente como femeninas, sino en los mismos espacios que los hombres, en la prensa regional diaria.

La apuesta por el diario La Verdad en reflejar las diversas opiniones sobre las cuestiones sociale, queda verificado en los casos presentados. Se plasma una considerable riqueza de contenido, especialmente ideológico, pues se reflejan posturas divergentes que son visibles con el correspondiente análisis del lenguaje utilizado en el discurso. Esta diversidad de ideas nos aproxima al carácter y personalidad del diario, que tiene la cualidad de proyectarse en el amplio y complejo abanico que constituye la sociedad murciana de la época y por ende, española. Además de distinguir los matices y opiniones respecto a la celebración del «Año Internacional de la Mujen», se han distinguido los matices entre los discursos de las «mujeres»y los «hombres». 